\title{
Chronic Intermittent Hypoxia Depresses Afferent Neurotransmission in NTS Neurons by a Reduction in the Number of Active Synapses
}

\author{
Carlos Eduardo L. Almado, Benedito H. Machado, and Ricardo M. Leão \\ Department of Physiology, School of Medicine of Ribeirão Preto, University of São Paulo, Ribeirão Preto, São Paulo 14049-900, Brazil
}

\begin{abstract}
Long-term synaptic plasticity has been recently described in brainstem areas associated to visceral afferent sensory integration. Chronic intermittent hypoxia $(\mathrm{CIH})$, an animal model for studying obstructive sleep apnea in humans, depresses the afferent neurotransmission in nucleus tractus solitarii (NTS) neurons, which affect respiratory and autonomic regulation. Here we identified the synaptic mechanisms of CIH-induced depression of the afferent neurotransmission in NTS neurons in juvenile rats. We verified that CIH reduced the amplitude of both NMDA and non-NMDA glutamatergic excitatory currents (eEPSCs) evoked by tractus solitarii stimulation (TS-eEPSC) of second-order neurons in the NTS. No changes were observed in release probability, evidenced by absence of any CIH-elicited effects on short-term depression and failures in EPSCs evoked in low calcium. CIH also produced no changes in TS-eEPSC quantal size, since the amplitudes of both low calcium-evoked EPSCs and asynchronous TS-eEPSCs (evoked in the presence of $\mathrm{Sr}^{2+}$ ) were unchanged. Using single TS afferent fiber stimulation in slices from control and CIH rats we clearly show that CIH reduced the quantal content of the TS-eEPSCs without affecting the quantal size or release probability, suggesting a reduction in the number of active synapses as the mechanism of CIH induced TS-eEPSC depression. In accordance with this concept, the input- output relationship of stimulus intensity and TS-eEPSC amplitude shows an early saturation in $\mathrm{CIH}$ animals. These findings open new perspectives for a better understanding of the mechanisms underlying the synaptic plasticity in the brainstem sensory neurons under challenges such as those produced by $\mathrm{CIH}$ in experimental and pathological conditions.
\end{abstract}

\section{Introduction}

The nucleus tractus solitarii (NTS) is the first central synaptic station for the cranial visceral afferents, including those carrying information from the cardiovascular and respiratory systems (Andresen and Kunze, 1994). This primary integration center processes different visceral afferent information, such as those arising from the arterial baroreceptors and chemoreceptors, whose integrated signals are sent to other important brainstem regions for the regulation of the autonomic and respiratory functions. Previous studies described activity-dependent plasticity mechanisms in the NTS circuitry, including short-term (Fortin et al., 1992; Chen et al., 1999) and long-term plasticity (Glaum and Brooks, 1996; Zhou et al., 1997), which may produce long-term changes in synaptic transmission after periods of intense afferent stimulation to the NTS.

\footnotetext{
Received June 1, 2012; revised Sept. 21, 2012; accepted Sept. 22, 2012.

Author contributions: C.E.L.A., B.H.M., and R.M.L. designed research; C.E.L.A. performed research; C.E.L.A. and R.M.L. analyzed data; C.E.L.A., B.H.M., and R.M.L. wrote the paper.

This work was supported by a fellowship from Fundação de Amparo a Pesquisa do Estado de São Paulo (FAPESP 2008/54953-0, C.E.L.A.) and FAPESP grants to R.M.L. (2008/04618-0) and B.H.M. (2009/50113-0). We thank Dr. Daniela Accorsi-Mendonça, Dr. Fusao Kato, and Leni G. H. Bonagamba for their important contributions to this work, Dr. Christopher Kushmerick for reviewing this manuscript, and Dr. Thanos Tzounopoulos for his insights on the data.

Correspondence should be addressed to Dr. Ricardo M. Leão, Department of Physiology, School of Medicine of Ribeirão Preto, University of São Paulo, Avenue Bandeirantes 3900, 14049-900, Ribeirão Preto, SP, Brazil. E-mail: leaor@fmrp.usp.br.

DOI:10.1523/JNEUROSCI.2654-12.2012

Copyright $\odot 2012$ the authors $\quad 0270-6474 / 12 / 3216736-11 \$ 15.00 / 0$
}

Chronic intermittent hypoxia $(\mathrm{CIH})$ in experimental animals is commonly used as a model for studying the autonomic and respiratory changes observed in obstructive sleep apnea, a pathology associated with several cardiorespiratory dysfunctions. $\mathrm{CIH}$ leads to long-term activation of peripheral chemoreceptors and baroreceptors producing episodic increases in the discharge of visceral afferents in the NTS (Fletcher et al., 1992; Vidruk et al., 2001; Peng et al., 2003; Zoccal et al., 2008, 2009). Additionally, $\mathrm{CIH}$ induces a sustained increased activity of TS afferents by enhancement of the resting discharge of carotid chemoreceptors (Peng et al., 2003). As a likely consequence of CIH-enhanced afferent activity in the NTS, CIH exposure results in a long-term synaptic depression in the NTS neurons (Kline et al., 2007).

Previous studies describing long-term depression (LTD) of NTS excitatory inputs after $\mathrm{CIH}$, documented, based on a decrease in the inverse of the squared coefficient of variation (1/ $\mathrm{CV}^{2}$ ) of EPSCs, that $\mathrm{CIH}$-induced depression was caused by a reduction in vesicle release probability (Kline et al., 2007). Surprisingly, given this hypothesis, short-term depression was not affected by $\mathrm{CIH}$, as would be expected if the depression was caused by a reduction in release probability (Brenowitz et al., 1998; Brenowitz and Trussell, 2001; Blitz et al., 2004; XuFriedman and Regehr, 2004; Yamamoto et al., 2010). One possible explanation is that because $1 / \mathrm{CV}^{2}$ is an index not only of $P_{R}$ but also of the number of functional synapses $(n)$, the observed reduction in the this parameter by $\mathrm{CIH}$ could reflect changes in the number of active synapses (Malinow and Tsien, 1990; 
Kerchner and Nicoll, 2008). Thus, the precise mechanisms of $\mathrm{CIH}$-induced depression in the NTS remain unclear.

In the present study we used a series of experimental approaches to evaluate the mechanisms of the $\mathrm{CIH}$-induced synaptic depression of TS-evoked neurotransmission in rats. Our data indicate that $\mathrm{CIH}$ depresses afferent neurotransmission in NTS neurons by a reduction in the number of functional synapses without affecting vesicle release probability at individual synapses or quantal size. Herein we describe a precise mechanism of synaptic plasticity in the NTS, which probably reflects an activitydependent adaptation of its afferents in response to a long-term overexcitation of visceral sensory inputs to second-order NTS neurons.

\section{Materials and Methods}

Animals. Juvenile male Wistar rats (19-21 d) were obtained from the Animal Care Facilities of the University of São Paulo, campus of Ribeirão Preto, Brazil. All experimental protocols were approved by the Ethical Committee on Animal Experimentation (CETEA, protocol 070/2007) of the School of Medicine of Ribeirão Preto, University of São Paulo.

$\mathrm{CIH}$. The animals were divided in two groups: $\mathrm{CIH}$ and control. The detailed $\mathrm{CIH}$ protocol used in the present study was previously described by Zoccal et al. (2008). Briefly, both groups were housed in collective cages and maintained inside Plexiglas chambers (volume, $210 \mathrm{~L}$ ) equipped with gas injectors as well as sensors for $\mathrm{O}_{2}, \mathrm{CO}_{2}$, humidity, and temperature. The $\mathrm{CIH}$ group was exposed to a protocol of $5 \mathrm{~min}$ of normoxia (inspired fraction of $\mathrm{O}_{2}, \mathrm{FIO}_{2}$, of $20.8 \%$ ) followed by $4 \mathrm{~min}$ of pure $\mathrm{N}_{2}$ injection to reduce the $\mathrm{FIO}_{2}$ from 20.8 to $6 \%$, remaining at this level for $40 \mathrm{~s}$. After this hypoxic period, pure $\mathrm{O}_{2}$ was injected into the chamber to return the $\mathrm{FIO}_{2}$ back to $20.8 \%$. This 9 min cycle was repeated $8 \mathrm{~h}$ a day (from 9:30 A.M. to 5:30 P.M.) for $10 \mathrm{~d}$. During the remaining $16 \mathrm{~h}$ the animals were maintained at a $\mathrm{FIO}_{2}$ of $20.8 \%$.

The injections of $\mathrm{N}_{2}$ and $\mathrm{O}_{2}$ (White Martins) into the chamber were regulated by a solenoid valve system whose opening-closing control was operated by a computerized system (Oxycycler; Biospherix). In a similar chamber in the same room, the control group was exposed to a constant $\mathrm{FIO}_{2}$ of $20.8 \%$ for $10 \mathrm{~d}$ with similar background noise. In both $\mathrm{CIH}$ and control chambers, the gases were injected at the upper level of the chamber to avoid stressing the animals by jets of gas impacting the animals.

Patch-clamp recordings. Horizontal brainstem slices were prepared after $10 \mathrm{~d}$ of exposure to $\mathrm{CIH}$ or normoxic (control) protocols. Rats were anesthetized with halothane and the brainstem was rapidly removed and placed in an ice-cold standard artificial CSF (aCSF) that contained the following (in mM): $125 \mathrm{NaCl}, 2.5 \mathrm{KCl}, 2 \mathrm{CaCl}_{2}, 1 \mathrm{MgCl}_{2}, 1.25 \mathrm{NaH}_{2} \mathrm{PO}_{4}$, 25 D-glucose, $0.4 \mathrm{~L}$-ascorbic acid, and $25 \mathrm{NaHCO}_{3}, \mathrm{pH} 7.4$, and bubbled with $95 \% \mathrm{O}_{2}+5 \% \mathrm{CO}_{2}$. The brainstem was mounted in a cutting stage of a vibrating blade slicer (Vibratome 1000 plus; Vibratome) and slices containing the NTS were obtained in a quasihorizontal orientation (Doyle et al., 2004). The slices were then incubated at $35^{\circ} \mathrm{C}$ for $30 \mathrm{~min}$ and after this period they were kept at room temperature $\left(22-25^{\circ} \mathrm{C}\right)$. For electrophysiological recordings each slice was transferred to a recording chamber ( $0.4 \mathrm{ml}$ volume) and fixed with nylon grids to a platinum frame. The slice was submerged and continuously superfused at a rate of 1-2 $\mathrm{ml} / \mathrm{min}$ with standard aCSF containing $20 \mu \mathrm{M}$ bicuculline (Sigma) to block GABAergic synaptic currents.

Patch electrodes were made from pulled thick-walled borosilicate glass capillaries (Sutter Instruments), using a programmable puller (Sutter P97; Novato). The composition of the intracellular solution contained the following (in $\mathrm{mm}$ ): $130 \mathrm{~K}$-gluconate, $20 \mathrm{KCl}, 10 \mathrm{HEPES}, 5$ EGTA, 2 $\mathrm{Mg}_{2} \mathrm{ATP}, 0.3 \mathrm{Na}_{2} \mathrm{GTP}$, and 5 phosphocreatin- $\mathrm{Na}_{2}$. The tip resistance of the electrodes ranged from 3 to $6 \mathrm{M} \Omega$ when filled with this solution. Neurons located in the caudal and intermediate NTS, more precisely in a region caudal to the rostral edge of area postrema, were preselected by visual identification with an upright microscope equipped with infrared differential interference contrast optics (BX-51; Olympus). During the recording, the membrane potential was held at $-70 \mathrm{mV}$. The access resistance was checked regularly during the recording and neurons with access resistance $>30 \mathrm{M} \Omega$ were discarded. Recordings of postsynaptic currents began $5 \mathrm{~min}$ after the whole-cell access was established. Recordings were made with an AxoPatch 200B patch-clamp amplifier connected to a PC computer via a DigiData 1440 Interface. Whole-cell currents were acquired using pClamp 10 (Molecular Devices), lowpass filtered at 2 $\mathrm{kHz}$, digitized at $10 \mathrm{kHz}$, and stored in a PC computer for off-line analysis. All experiments were performed at room temperature $\left(22-25^{\circ} \mathrm{C}\right)$.

Stimulation of the solitary tract. Evoked EPSCs (eEPSCs) were generated by placing a concentric bipolar stimulating electrode (Frederick Haer) on the ipsilateral solitary tract (TS) at least $1.5 \mathrm{~mm}$ cranially to the neuron to be recorded and stimulated at a duration of $0.3 \mathrm{~ms}$ with an isolated stimulator (D2A; Digitimer). Stimulation was delivered every $10 \mathrm{~s}$. The intensity of TS stimulation was progressively increased until an eEPSC was evoked. When an additional increase in the intensity did not alter eEPSC amplitude, it was considered as the maximum response. For study of synaptic depression we used a train of five stimuli at $33 \mathrm{~Hz}$. For the calcium dose-response curve and variance-mean analysis we measured TS-EPSCs in different calcium concentrations $(0.1,0.25,0.5,1,2$, and $4 \mathrm{~mm}$ ). In this set of experiments, $\mathrm{Mg}^{2+}$ concentration was adjusted to keep the overall divalent cation concentration constant when using $\mathrm{Ca}^{2+}$ concentrations $<2 \mathrm{~mm}$, and kept at $1 \mathrm{~mm}$ when using $4 \mathrm{~mm} \mathrm{Ca}^{2+}$. Slices were perfused for at least $10 \mathrm{~min}$ with each of the aCSF containing different $\mathrm{Ca}^{2+}$ concentration before starting recording.

NMDA TS-eEPSCs recordings. TS-evoked NMDA currents were recorded at a holding potential of $+40 \mathrm{mV}$, using an intracellular solution designed to reduce the voltage-activated potassium conductances to minimize background noise. This solution was composed of the following (in mM): 130 Cs-methanesulfonate, $20 \mathrm{CsCl}, 10$ HEPES, 5 EGTA, 2 $\mathrm{Mg}_{2} \mathrm{ATP}, 0.3 \mathrm{Na}_{2} \mathrm{GTP}, 5$ phosphocreatin- $\mathrm{Na}_{2}$, and 5 tetraethylammonium. At least 15 trials were recorded at $+40 \mathrm{mV}$ in the presence of bicuculline, and then $40 \mu \mathrm{M}$ DL-AP5 were added to perfusion to selectively block the NMDA component of the TS-eEPSC. At least 15 TSeEPSCs were recorded in the presence of bicuculline and DL-AP5. Subsequently, the mean NMDA TS-eEPSC was calculated by subtracting the mean AMPA TS-eEPSC (in the presence of DL-AP5) from the total TS-eEPSC obtained in the absence of DL-AP5 (see Fig. $2 A$ ).

Recording of asynchronous TS-eEPSCs. Equimolar replacement of external $\mathrm{Ca}^{2+}$ by $\mathrm{Sr}^{2+}(2 \mathrm{~mm})$ leads to a desynchronization of TS-eEPSCs in their quantal units, named asynchronous TS-EPSCs (aEPSCs), allowing the calculation of the quantal content $(m)$ of the regular TS-eEPSCs (Oliet et al., 1996; Bekkers and Clements, 1999; Xu-Friedman and Regehr, 2000). After recording at least 15 trials in the normal $\mathrm{Ca}^{2+}$ condition, $\mathrm{Sr}^{2+}$-containing aCSF was perfused for at least $10 \mathrm{~min}$ to assure complete exchange of $\mathrm{Ca}^{2+}$ by $\mathrm{Sr}^{2+}$. Thereafter, 30-40 trials were recorded. For aEPSC analysis, the first TS-evoked EPSC (which is usually composed with less asynchronous currents) was discarded, and the subsequent aEPSCs were analyzed using a time window of $200 \mathrm{~ms}$ from the stimulus artifact. By discarding the first aEPSC from the analysis procedure, we reduced the influence of occasional multiquantal/nondesynchronized TS-eEPSCs in our analyses. The $200 \mathrm{~ms}$ analysis time window for the aEPSCs had two purposes: (1) to minimize the contamination of our aEPSCs by spontaneous EPSCs that can originate from non-TS synapses and (2) to reduce the influence of the asynchronous EPSCs that have been described to occur in some TS synapses even in the absence of $\mathrm{Sr}^{2+}$ (Peters et al., 2010).

Minimal TS stimulation or single TS fiber stimulation. To obtain a single quantal current we used the technique of minimal stimulation of single axonal afferent TS fiber (Raastad et al., 1992; Allen and Stevens, 1994; Stevens and Wang, 1994; Isaac et al., 1996; Dobrunz and Stevens, 1997; Franks and Isaacson, 2006). Theta glass electrodes (Sutter Instruments) were pulled to obtain tips of 1-3 $\mu \mathrm{m}$ diameter. After being filled with aCSF and connected to an isolated stimulator using silver wires, the theta electrode was placed over the TS at an intermediate position between the concentric bipolar electrode (used for multifiber stimulation) and the recorded cell. Pulses were applied while adjusting stimulus intensity and/or the position of the theta electrode onto the TS to find conditions of minimal stimulation. To be considered a "minimal" synaptic current (single fiber) the following criteria were required: (1) it was produced with the minimal intensity of stimulus necessary to evoke synaptic cur- 
A

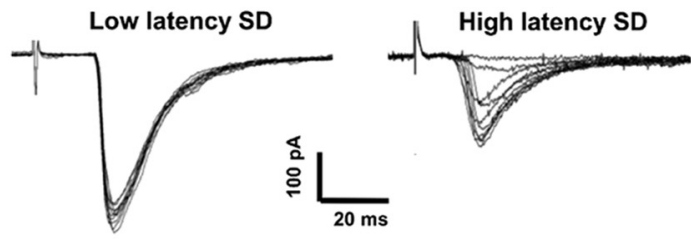

B

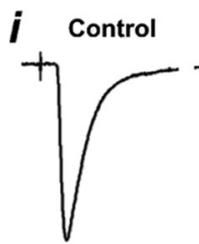

D

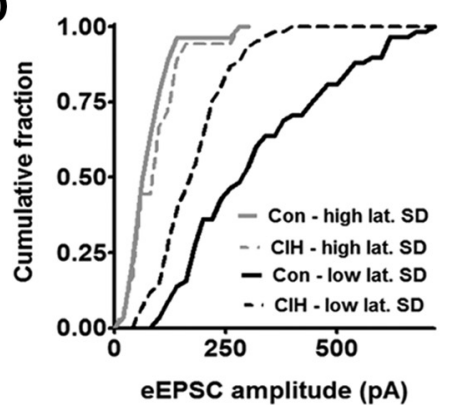

eEPSC amplitude (pA)
$\mathrm{CIH}$<smiles>CCCCCCCC</smiles>

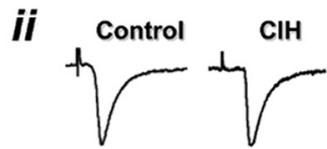

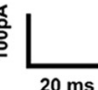
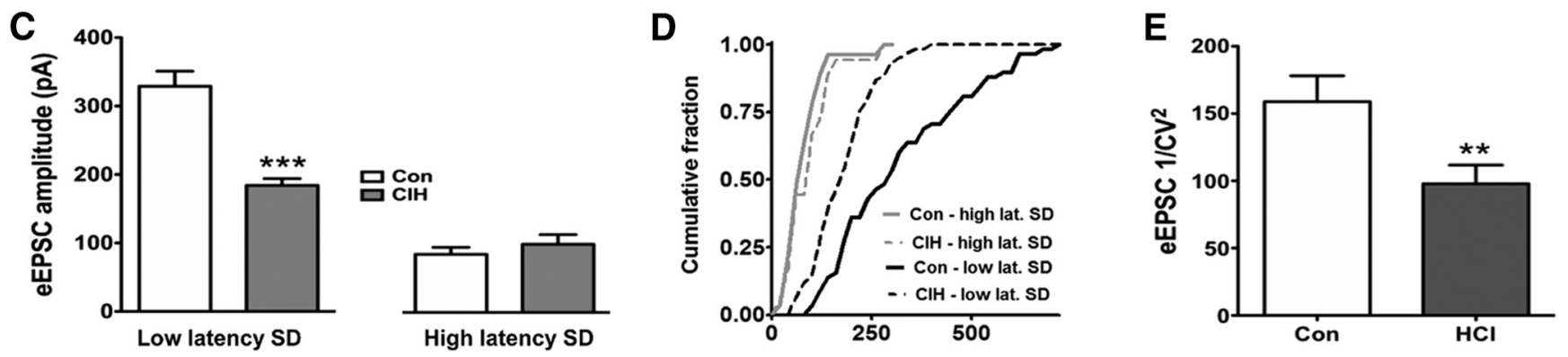

Figure 1. CIH selectively depresses low variability TS-eEPSCS. A, Representative examples of EPSCS evoked by TS stimulation in a low latency-SD NTS neuron (left) and in a high latency-SD NTS (right). The traces represent 10 superimposed eEPSCS. Notice the very low variability of the eEPSC latency onset from the low latency-SD NTS neuron and the high variability in the latency and presence of failures of the eEPSCs from high latency-SD neurons. $\boldsymbol{B}$, Representative traces of TS-eEPSCs from low latency-SD (i) neurons and high latency-SD (ii) neurons, from control and CIH animals. The traces represent an average of 20 TS-eEPSCS. C, Mean peak amplitudes of the TS-eEPSCs after $10 \mathrm{~d}$ of normoxic (Con) or CIH exposure from low latency-SD NTS neurons (Con, $n=58$; $\mathrm{CIH}, n=59$ ) and high latency SD-NTS neurons (Con, $n=27 ;(\mathrm{IH}, n=18) .{ }^{* * *} p<0.0001$, Mann-Whitney test. $\boldsymbol{D}$, Cumulative frequency distribution of the amplitudes of TS-eEPSCS from low latency-SD and high latency-SD NTS neurons from control and CIH animals. $E$, Comparison of the inverse of squared coefficient of variation (1/CV $\left.{ }^{2}\right)$ of low latency-SD neurons from Con and CIH animals. ${ }^{* *} p=0.009$, Mann-Whitney test.

rents and (2) the distribution of the synaptic currents' amplitudes followed a single Gaussian curve. Minimal stimulation EPSCs that presented amplitude distributions not following a single Gaussian distribution were considered multifiber EPSCs and excluded from the analysis.

Data analysis. All final membrane potential values took into account a calculated liquid junction potential of $-14 \mathrm{mV}$. The recorded synaptic currents were analyzed off-line using Clampfit version 10 (Molecular Devices). Spontaneous postsynaptic currents were recorded for 2 min and their frequency, amplitude and half-width were analyzed with the Mini-Analysis Program version 5.0 (Synaptosoft). For the short-term synaptic depression analysis, eEPSC failures were included in the calculation. The latency for eEPSC initiation was calculated manually as the time from the stimulus artifact to the onset of the evoked current, which was determined as the first data point that exceeded 2 SDs of the baseline noise. Subsequently, we calculated the SD of eEPSC latency for at least 15 eEPSCs. The $V-M$ analysis was performed as described by AccorsiMendonça et al. (2011). Briefly, we recorded 40-50 TS-EPSCs in each extracellular calcium concentration, and the mean TS-eEPSC amplitude $(M)$ for each condition was calculated taking the failures into account and plotted against their variance $(V)$. Individual plots were fitted with a quadratic polynomial equation assuming zero variance in zero amplitude. The binomial parameters quantal size $(q)$ and number of release sites $(n)$ were expressed in the equation as follows: $V=q M-M^{2} / N$. The release probability $\left(P_{R}\right)$ was estimated by calculating the maximum EPSC amplitude (given by the binomial distribution N.q) and dividing it by the EPSC amplitude in $2 \mathrm{~mm}$ calcium.

Statistical analysis was performed with GraphPad Prism (version 5.0; GraphPad Software) and the on-line software Statistics to Use (www. physics.csbsju.edu/stats/). Statistical comparison was made using MannWhitney $U$ test, Kruskal-Wallis test, ANOVA test, Student's $t$ test, or the Kolmogorov-Smirnov (K-S) test (for distributions comparison). The data are expressed as mean \pm SEM and significance level was set as $p<0.05$.

Salts, drugs, and reagents. Bicuculline free-base, baclofen, DL-AP5, and tetrodotoxin (TTX) were purchased from Tocris Bioscience and Sigma. All reagents and salts were from analytical grade. Solutions were prepared using ultrapure water (resistivity $>18.2 \mathrm{M} \Omega \cdot \mathrm{cm}^{-1}$ ) obtained from a Direct-Q UV System (Millipore).

\section{Results}

CIH decreases glutamatergic eEPSC amplitude in NTS neurons with low $\mathrm{SD}$ of the synaptic latencies

It was demonstrated (Kline et al., 2007) that $\mathrm{CIH}$ produced a synaptic depression in second-order neurons in the NTS identified on the basis of the SD of the synaptic latencies (Doyle and Andresen, 2001). Recently, Accorsi-Mendonça et al. (2011) showed that chemosensory second-order neurons receive afferents from the carotid body (CB) with TS-eEPSC SD of latencies higher than the initially proposed cutoff of $0.2 \mathrm{~ms}$ to define second-order neurons in the NTS, which was based on measurements in neurons receiving afferent inputs from arterial baroreceptors (Doyle and Andresen, 2001; Bailey et al., 2006). To verify if the CIH-induced depression could also be observed in the NTS neurons with TS-eEPSCs with SD of latencies in the range observed in chemosensory neurons $(>0.2 \mathrm{~ms})$, we compared the effect of CIH on the TS-eEPSC in low latency SD synapses (Accorsi-Mendonça et al., 2011; $<0.25 \mathrm{~ms}$ ) with its effect on neurons with higher latency SD synapses $(0.25 \mathrm{~ms})$ (Fig. 1A). We observed that $\mathrm{CIH}$ produced, as previously described by Kline et al. (2007), a reduction of the TS-eEPSCs in low latency SD NTS synapses (Con: $325.1 \pm 22.1 \mathrm{pA}, n=58$ vs $\mathrm{CIH}=$ $186.6 \pm 10.6 \mathrm{pA}, n=59$; $t$ test, $p<0.0001$; Fig. $1 B i, C, D$ ), while the amplitude of the TS-eEPSCs of high latency SD synapses was not affected (Con: 102.2 $\pm 19.3 \mathrm{pA}, n=27$ vs $\mathrm{CIH}=$ $99.5 \pm 14.1 \mathrm{pA}, n=18$; $t$ test, $p=0.92$; Fig. 1 Bii, $C, D)$. As seen previously by Kline et al. (2007), we also verified a reduction in the inverse of $1 / \mathrm{CV}^{2}$ of the TS-eEPSCs from low latency SD synapses (Fig. 1E). These data show that the effect of $\mathrm{CIH}$ occurs only in synapses from the TS presenting a low eEPSC latency SD, and for this reason, all subsequent experimental protocols were planned to explore the mechanisms underlying the CIH-induced depression of the TS-eEPSCs on this specific neuronal population. 
A

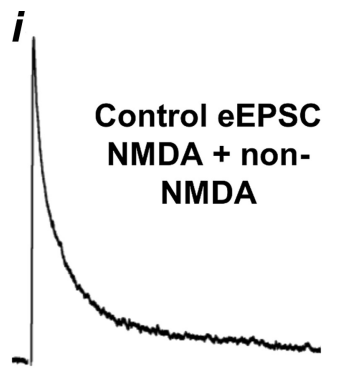

ii
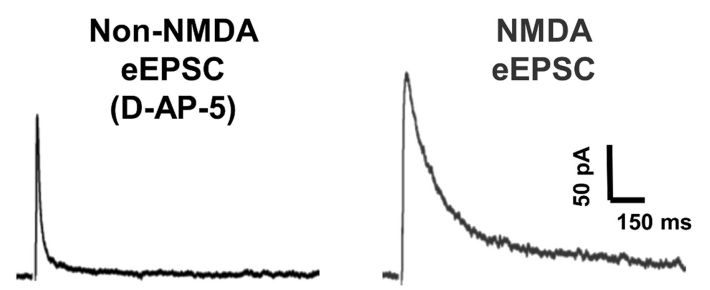

Control

B

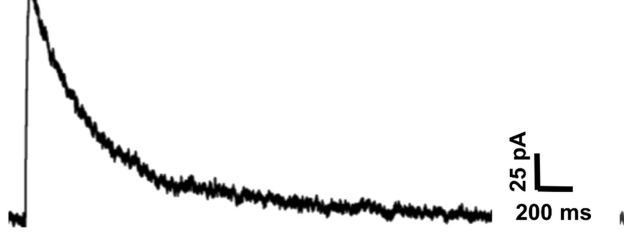

C

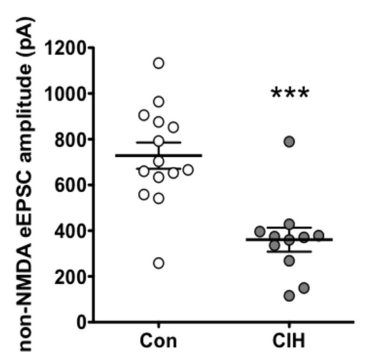

D

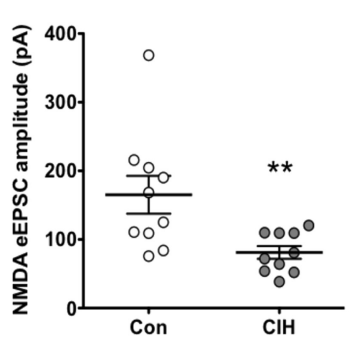

E

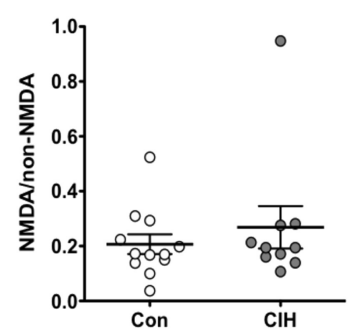

Figure 2. CIH depresses Ts-evoked NMDA currents. A, Representative traces of an eEPSC corresponding to the average of 15 eEPSCs evoked at $40 \mathrm{mV}$, before (i) and after (ii) application of the NMDA receptor antagonist DL-AP5 (40 $\mu \mathrm{m}$ ). iii, NMDA current obtained by the subtraction of trace ii from trace $\boldsymbol{i}$. $\boldsymbol{B}$, Representative traces of NMDA TS-eEPSCs obtained in low latency-SD NTS neurons from control (Con) and CIH animals. C, Mean amplitude of the non-NMDA and (D) NMDA eEPSCs (recorded in the same neurons) from Con and CIH animals. ${ }^{* * *} p=0.0001$, unpaired $t$ test; ${ }^{* *} p=0.0052$, Mann-Whitney test. $E$, Comparison of the ratio of NMDA and non-NMDA currents in NTS neurons from Con and CIH animals. Symbols represent the mean response from individual neurons and the lines the mean \pm SEM.

\section{CIH equally affects TS-evoked NMDA and non-NMDA currents}

The decrease in the $1 / \mathrm{CV}^{2}$ is compatible with a presynaptic mechanism of depression. A reduction in the release of glutamate would affect in a similar manner both NMDA and non-NMDA TS-eEPSCs, whereas postsynaptic affects might differentially affect the NMDA and non-NMDA currents. To test this hypothesis, we evaluated the effect of CIH on NMDA and non-NMDA TS-eEPSCs recorded in the same cells (Fig. 2A). Our data show that both non-NMDA (Con: $732 \pm 77 \mathrm{pA}, n=10$; CIH: $382 \pm 53$ pA, $n=10$; $p<0.01$; Fig. $2 B$ ) and NMDA eEPSCs (Con: $165 \pm$ 27 pA, $n=10$; CIH: $81 \pm 9$ pA, $n=10$; $p<0.01$; Fig. $2 B-D)$ were significantly depressed by $\mathrm{CIH}$. In addition, the ratio between NMDA and non-NMDA TS-eEPSCs was similar in control and CIH (Con: $0.235 \pm 0.047$; CIH: $0.268 \pm 0.077 ; p=0.85$; Fig. $2 E$ ), supporting the concept that $\mathrm{CIH}$ affects both NMDA and nonNMDA glutamatergic neurotransmission in NTS neurons.

\section{CIH does not change release probability}

The reduction of the $1 / \mathrm{CV}^{2}$ and an observed similar depression of the NMDA and non-NMDA components suggest that the site of the depression is presynaptic. However, if this depression was a consequence of a reduction in the release probability the short-
CIH

term plasticity of the TS-eEPSCs would be changed, because it is strongly affected by changes in the release probability (Brenowitz et al., 1998; Blitz et al., 2004; Xu-Friedman and Regehr, 2004; Yamamoto et al., 2010). A decrease in the release probability would produce a smaller depletion of the vesicle releasable pool, which in turn, leads to a less pronounced synaptic depression (Brenowitz et al., 1998; Xu-Friedman and Regehr, 2004). To test the hypothesis that $\mathrm{CIH}$ changes the release probability we compared the amount of short-term synaptic depression of TS-eEPSCs in NTS neurons, from both control and CIH rats. Trains of five stimuli delivered at $33 \mathrm{~Hz}$ produced significant depression of TS-eEPSCs (Fig. $3 A$ ), which at this range is not influenced by receptor desensitization (Chen et al., 1999). When the eEPSCs were normalized to the peak amplitude of the first eEPSC, we observed that the magnitude of depression was similar in both groups [second, third, fourth, and fifth normalized TS-eEPSCs (Con: $32 \pm 3,24 \pm 3,20 \pm 3$, and $20 \pm 3 \%, n=50)$ vs (CIH: $32 \pm 3$, $27 \pm 3,23 \pm 2$, and $24 \pm 2 \%, n=52$ ), two-way ANOVA, $F_{(1,497)}=1.95, p=$ 0.16 ; Figure $3 A, B]$, a finding consistent with a lack of effect on release probability. In addition, we verified a significant increase in the number of failures during the high-frequency train in the $\mathrm{CIH}$ group [percentage of failures for the first, second, third, fourth, and fifth TSeEPSC of each train (Con: $0 \pm 0,11.5 \pm$ $3.5,12.6 \pm 2.9,24.0 \pm 4.0$, and $23.7 \pm$ $3.7 \%, n=50)$ vs (CIH: $0.1 \pm 0.1,23.5 \pm$ $4.6,23.7 \pm 23.7,33.3 \pm 4.0$, and $37.4 \pm 4.1 \%, n=52)$, twoway ANOVA, $F_{(1,500)}=17.91, p<0.0001$; Bonferroni posttest, fifth eEPSC Con vs CIH, $p<0.05$; Figure $3 C$ ].

The similar short-term depression in both control and $\mathrm{CIH}$ groups is not consistent with a model of synaptic depression by a decrease in vesicular release probability. To validate this prediction in our preparation, we compared the effects of two approaches known to produce a reduction in the amplitude of the TS-eEPSCs by distinct mechanisms: (1) application of baclofen, a $\mathrm{GABA}_{\mathrm{B}}$ agonist $(10 \mu \mathrm{M})$, which reduces the release probability and (2) application of submaximal concentrations of 6,7-dinitroquinoxaline-2,3-dione (DNQX), an AMPA/kainate receptor antagonist $(2 \mu \mathrm{M})$, which decreases the receptor availability. In accordance with findings from other preparations, we expected that application of baclofen should produce a decrease in the synaptic short-term depression and DNQX should not change the amount of the short-term depression (Brenowitz et al., 1998; Tzounopoulos et al., 2007). Accordingly, we observed that while both approaches decreased the amplitude of the TSeEPSCs to similar levels as CIH (baclofen: from $424 \pm 49 \mathrm{pA}$ to $191 \pm 43 \mathrm{pA}, n=5$; paired $t$ test, $p=0.0009$; Fig. $4 A i, B i$ ) (DNQX: from $318 \pm 45 \mathrm{pA}$ to $195 \pm 43 \mathrm{pA}, n=5$; paired $t$ test, $p=0.0003$; Fig. 4 Aii,Bii), the magnitude of short-term depression was reduced only by baclofen [second, third, fourth, and fifth normal- 
ized eEPSCs: (Pre: $22 \pm 2,16 \pm 3,11 \pm 2$, and $12 \pm 1 \%, n=5$ ) vs (baclofen: $46 \pm 7$, $42 \pm 11,39 \pm 10$, and $32 \pm 10 \%, n=5$ ), two-way ANOVA, $F_{(1,40)}=24.22, p<$ 0.0001 ; Figure $4 C]$. It is also important to note that only baclofen reduced the $1 / \mathrm{CV}^{2}$ of TS-eEPSCs (baclofen: $24.9 \pm 10.6 \%$ from control, $n=5$; paired $t$ test, $p=$ 0.0021; Fig. $4 D$ ). This observation supports the concept that any reduction of eEPSC amplitude by presynaptic mechanisms implies a concurrent reduction of $1 / \mathrm{CV}^{2}$. An additional support to this concept is the fact that DNQX, which has a postsynaptic site of action, produced no changes in $1 / \mathrm{CV}^{2}$ (DNQX: $113.9 \pm 30.4 \%$ from control, $n=5$; paired $t$ test, $p=0.6719$; Fig. $4 D)$.

These experiments with baclofen have clearly shown that a decrease in the vesicular release probability in NTS synapses produce a reduction in both the shortterm synaptic depression and the $1 / \mathrm{CV}^{2}$. On the other hand, experiments with low DNQX concentration demonstrated that a decrease in the number of receptors or conductance does not affect short-term plasticity or $1 / \mathrm{CV}^{2}$. $\mathrm{CIH}$, in turn, reduced only the $1 / \mathrm{CV}^{2}$ of the eEPSCs, not affecting short-term depression, an effect not compatible with either a reduction in vesicular release probability or with a reduced receptor number or conductance. Subsequent series of experiments were performed to better assess the origin of this discrepancy and investigate the precise mechanisms of $\mathrm{CIH}$-induced depression of the TSeEPSCs.

\section{CIH does not change the TS-eEPSCs evoked in low $\mathrm{Ca}^{2+}$}

The data presented above suggest that CIH reduces the TS-eEPSC by a mechanism distinct from a purely reduced release probability or receptor number/conductance. In agreement with this hypothesis we did not observe any changes induced by $\mathrm{CIH}$ in the parameters of the miniature spontaneous synaptic currents (recorded in the presence of $1 \mu \mathrm{M}$ TTX), which are affected by changes in release probability (frequency) or in receptor number/ conductance (amplitude and half-width) (Table 1). Considering that these currents could originate from non-TS synapses, which might not be affected by CIH, we also analyzed TS-evoked currents in conditions of very low release probability, which produce quantal or near-quantal events. For this, TS-eEPSCs in NTS neurons from control and $\mathrm{CIH}$ animals were recorded in low calcium/high magnesium conditions $(0.2 \mathrm{~mm} / 3 \mathrm{~mm}$, respectively). Under this experimental condition we verified that the peak amplitude of the eEPSCs was dramatically reduced (Fig. 5A) and most of the trains produced failures. Surprisingly, the distributions of the amplitudes of TS-eEPSCs evoked under the low calcium condition were similar in both groups, showing no shift to smaller amplitudes (K-S test, $p=0.99$; Fig. $5 B)$. We also verified that the mean amplitude of the low calcium TS-eEPSCs was not statistically different between neurons from both control and CIH groups (Con: $34.3 \pm 2.7 \mathrm{pA}, n=12 \mathrm{vs} \mathrm{CIH:} 33.9 \pm 3.9 \mathrm{pA}$, $n=12 ; p=0.93$; Fig. $5 B)$. These results strongly support the concept that the minimal synaptic current is not reduced by $\mathrm{CIH}$.
We then asked whether the $\mathrm{CIH}$-induced reduction of the TS-eEPSC could be a result of an altered sensitivity of synaptic exocytosis to extracellular calcium. For this we analyzed the dependence of both TS-EPSC amplitude and failure rate to a broad range of extracellular $\mathrm{Ca}^{2+}$ concentrations (0.1-4 mM). Contrary to the hypothesis of a different calcium relationship of synaptic vesicle exocytosis after $\mathrm{CIH}$, we found that TS-eEPSC amplitude had the same $\mathrm{Ca}^{2+}$ dependence in both groups, with similar $\mathrm{EC}_{50}$ (Con: $0.92 \pm 0.03 \mathrm{~mm}, n=11$ vs $\mathrm{CIH}: 0.92 \pm 0.03 \mathrm{~mm}$; extra sum-of-squares $F$ test, $F_{(1,117)}=0.0529, p=0.818$; Fig. $\left.5 D\right)$ and Hill slope (Con: $1.75 \pm 0.19, n=11$ vs CIH: $1.71 \pm 0.18$; extra sum-ofsquares $F$ test, $F_{(1,117)}=0.0357, p=0.850$; Fig. $\left.5 D\right)$. Concerning the $\mathrm{Ca}^{2+}$ dependence of the failure rate, we observed no changes in Hill slope (Con: $-4.51 \pm 0.51, n=11$ vs CIH: $-4.31 \pm 0.38$; extra sum-of-squares $F$ test, $F_{(1,117)}=0.0987, p=0.754$; Fig. $\left.5 E\right)$, which reinforces the findings suggesting that $\mathrm{CIH}$ produces no changes in calcium-release relationship of synaptic vesicles. Altogether, these data clearly show that the exocytosis and $\mathrm{Ca}^{2+}$ dependence of NTS synapses is not affected by $\mathrm{CIH}$, which also rules against changes in vesicle release probability produced by $\mathrm{CIH}$. Nevertheless, we verified a significant increase (rightward shift) in the $\mathrm{IC}_{50} \mathrm{of} \mathrm{Ca}^{2+}$ doseresponse curve for failure rate (Con: $0.30 \pm 0.01 \mathrm{~mm}, n=11 \mathrm{vs} \mathrm{CIH:}$ $0.34 \pm 0.01 \mathrm{~mm}$; extra sum-of-squares $F$ test, $F_{(1,117)}=4.742, p=$ 0.031 ; Fig. 5E). This finding is in agreement with our results showing an increased number of failures during the high-frequency train of stimulation after $\mathrm{CIH}$ exposure. Both results point to a possible reduction in the quantal content $(m)$ of TS-EPSCs.

$\mathrm{CIH}$ produces a reduction in the quantal content $(m)$ of the TS-eEPSCs by reducing the number of available quanta $(n)$ Our data clearly show that the mechanisms of $\mathrm{CIH}$-induced synaptic depression are more complex than a simple presynaptic decrease on release probability or a postsynaptic reduction in the 

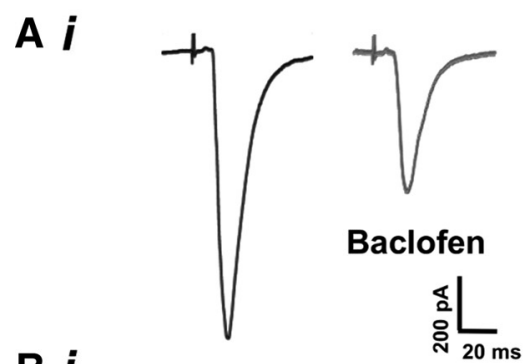

B $i$

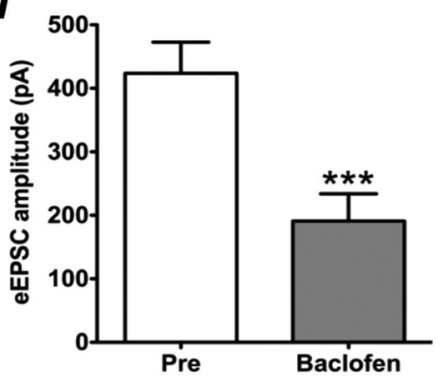

C $i$

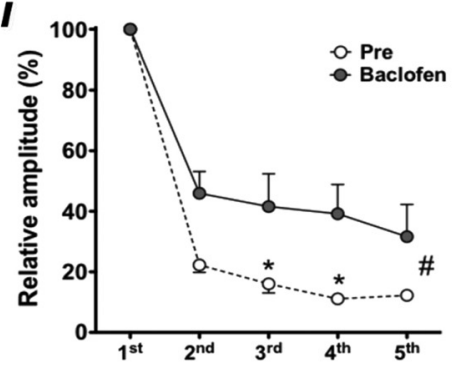

D $i$

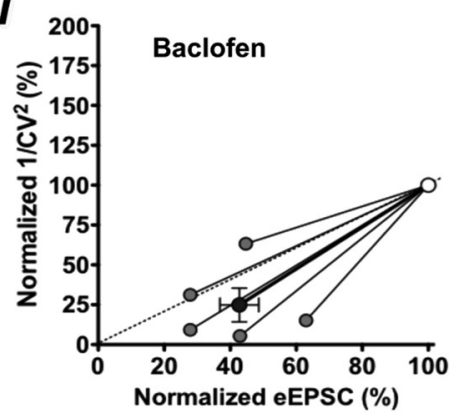

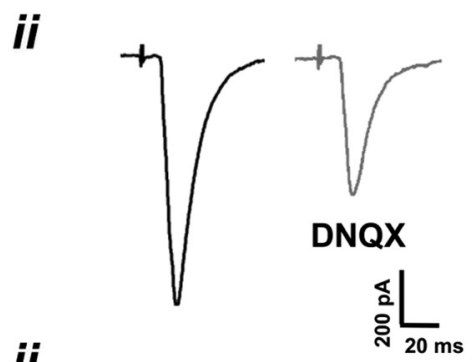
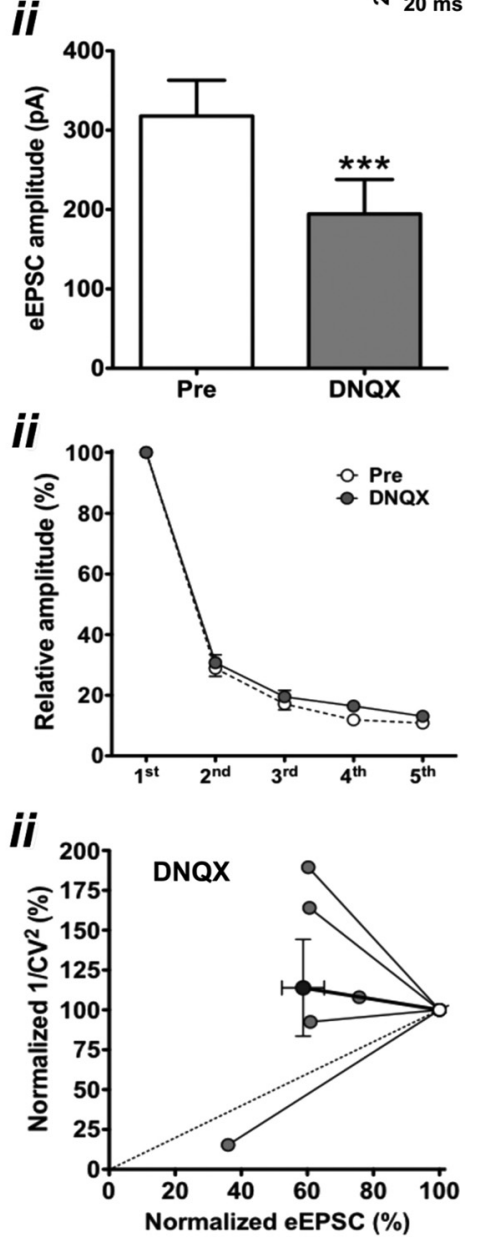

Figure 4. Short-term depression of the TS-eEPSC in conditions of reduced release probability and reduced receptor occupancy. $\boldsymbol{A}$, Representative traces of eEPSCs before (black trace) and after (gray trace) the application of baclofen $10 \mu \mathrm{m}$ (i) or DNQX $1 \mu \mathrm{m}$ (ii). $\boldsymbol{B}$, Summary of the effect of baclofen (i) and DNQX (ii) on the peak eEPSCamplitude. ${ }^{* * *} p=0.0003$, paired $t$ test, $n=5$, for baclofen; ${ }^{* * *} p=$ 0.0009 , paired $t$ test, $n=5$, for DNQX. C, Effect of baclofen (i) and DNQX (ii) on the short-term depression. The figures show the relative efficacy of the TS-eEPSCs during a train of five stimuli at $33 \mathrm{~Hz}$. For baclofen: ${ }^{\#}<<0.0001$, two-way ANOVA, $n=5 ;{ }^{*} p<0.05$, Bonferroni post-test, third and fourth eEPSCs different from control. For DNQX: $n=5$. D, Plot of the effect of baclofen (i) and DNQX (ii) on the normalized $1 / \mathrm{CV}^{2}$ in relation to the TS-eEPSC amplitude reduction. Only baclofen reduces TS-eEPSC amplitude with a concurrent effect on $1 / \mathrm{CV}^{2}$. The mean \pm SEM of all data is shown in the black circle. The dotted line represents a perfect correlation of the two variables.

quantal size. According to the classical model of quantal neurotransmitter release described by Del Castillo and Katz (1954), quantal content, $m$, is defined by the product of the quantal size (the minimal synaptic current, $q$ ), release probability $\left(P_{R}\right)$, and the number of available quanta $(n)$. Since we observed no changes in release probability $\left(P_{R}\right)$ and quantal size $(q)$, the most likely possibility for explaining the $\mathrm{CIH}$-induced synaptic depression is a reduction in the number of available quanta $(n)$, which reflects the number of releasable vesicles, active zones, and/or terminals. A reduced number of available quanta would produce depression of the TS-eEPSCs without altering short-term synaptic depression with a decrease in the $1 / \mathrm{CV}^{2}$ of the eEPSC
(Malinow and Tsien, 1990; Kerchner and Nicoll, 2008), similar to our observation for $\mathrm{CIH}$. The quantal parameters can be estimated by a stationary fluctuation analysis, known as variance-mean analysis $(V-M)$ of the EPSCs, which is achieved by changing vesicle release probability manipulating the amount of external $\mathrm{Ca}^{2+}$ (Clements and Silver, 2000; Clements, 2003, Yamamoto et al., 2010; Accorsi-Mendonça et al., 2011). We then analyzed the data from our calcium doseresponse curve to obtain the $V-M$ plots (Fig. 6A). After fitting the data with a second-degree polynomial equation we obtained the estimated parameters $q, P_{R}$, and $n$. We found that while $P_{R}$ and $q$ were similar in both control and $\mathrm{CIH}$ groups $\left(P_{R}\right.$ : Con: $0.81 \pm 0.03, n=10$ vs $\mathrm{CIH}$ : $0.79 \pm 0.06, n=8 ; p=0.727$; Fig. $6 B ; q$ : Con: $24.5 \pm 3.3 \mathrm{pA}, n=10$ vs CIH: $31.2 \pm$ $4.9 \mathrm{pA}, n=8 ; p=0.254$; Fig. $6 C$ ), $n$ was much smaller in $\mathrm{CIH}$ synapses ( $n$ : Con: $31 \pm 5, n=10$ vs $\mathrm{CIH}: 16 \pm 1, n=8 ; p=$ 0.046 ; Fig. $6 D$ ). This result strongly suggests that $n$ is the parameter affected by $\mathrm{CIH}$ and we proceed to obtain more direct experimental evidence corroborating this model.

To assess the hypothesis of a $\mathrm{CIH}$ induced reduction in TS-eEPSC parameter $n$, we first used a manipulation that allowed us to estimate the number of quanta released for each stimulus using strontium $\left(\mathrm{Sr}^{2+}\right)$, which decomposes the TS-eEPSCs in their quantal currents (Oliet et al., 1996; Bekkers and Clements, 1999; Xu-Friedman and Regehr, 2000). With this approach its is possible to evaluate the number of quanta released by each TS stimulation, i.e., the TS-eEPSC quantal content, $m$. Using equimolar replacement of $\mathrm{Ca}^{2+}$ by $\mathrm{Sr}^{2+}(2 \mathrm{mM})$, we verified that the stimulation of the TS clearly produced smaller aEPSCs (Fig. $7 A$ ). Consistent with the idea of a reduced number of quanta released, we observed that the average number of aEPSCs produced per trial was significantly reduced in neurons from $\mathrm{CIH}$ rats (Con: $4.7 \pm 0.7$, $n=10$ vs CIH: $2.3 \pm 0.4, n=10 ; p=0.01$; Fig. $7 B$ ). On the other hand, a normalized histogram shows that the distribution of aEPSCs amplitudes in both control and $\mathrm{CIH}$ groups were similar (Fig. 7C). These histograms can be fitted with a double Gaussian function and we considered the peak of the first Gaussian as the mean amplitude of the uniquantal events for each analyzed neuron (Fig. 7C). The amplitudes of the uniquantal aEPSCs were similar in both groups (Con: $17.9 \pm 1.1 \mathrm{pA}, n=$ 10 vs CIH: $17.9 \pm 0.7, n=10 ; p=0.97$; Fig. $7 D$ ). Considering that we demonstrated that release probability is not altered in neurons from $\mathrm{CIH}$ rats, the most likely explanation for the reduction in the number of aEPSCs per trial is a reduced number of available quanta, i.e., the parameter $n$. 
Minimal stimulation experiments show a reduction in the number of active synapses in the NTS neurons induced by $\mathrm{CIH}$

To provide further evidence to confirm the hypothesis of a $\mathrm{CIH}$ induced reduction in the number of available synapses, we performed experiments of minimal stimulation of the TS using theta glass electrodes. This protocol allows the detection of the minimal response to a stimulus applied to a single TS afferent fiber, which corresponds to a quantal event.

Minimal stimulation of the TS by a theta glass electrode (Fig. $8 A$ ) produced small eEPSCs elicited in an all-or-none pattern, whose amplitude and latency were consistently regular (Fig. $8 \mathrm{~B}$ ). This pattern of response likely represents the release of a single vesicle (quanta). Confirming this observation, we verified that the amplitude distribution of single-fiber EPSCs (sfEPSCs) was unimodal in both control and $\mathrm{CIH}$ conditions, supporting the concept that these minimal EPSCs represent a single quantal unit originated from an sfEPSC (Fig. 8C). Interestingly, we observed that the amplitude of the minimal sfEPSC was slightly smaller $(-9 \%)$ in the $\mathrm{CIH}$ group (Con: $17.6 \pm 0.6$ $\mathrm{pA}, n=22$, vs CIH: $16.0 \pm 0.5 \mathrm{pA}, n=22$, $p=0.042$; Fig. $8 D$ ) while the TS-eEPSCs in these neurons were greatly reduced ( $-54 \%$; Con: $417 \pm 38$ pA, $n=22$, vs $\mathrm{CIH}: 191 \pm 18 \mathrm{pA}, n=22, p<0.0001$; Fig. $8 \mathrm{E}$ ). Although we detected a small decrease in the amplitude of the quantal eEPSC induced by $\mathrm{CIH}$, it is very unlikely that this minimal effect was the cause of the pronounced depression observed in the total TS-eEPSC. Indeed, we found no correlation between the amplitude of the sfEPSC and the multifiber (total) TSeEPSC in control as well as in $\mathrm{CIH}$ neurons (Con: Spearman correlation coefficient $=-0.2964, p=0.1804$; CIH: Spearman correlation coefficient $=-0.0401$, $p=0.8594$; Fig. $8 F$ ), suggesting that the main factor determining the amplitude of TS-EPSCs is the $n$, and not the quantal amplitude, $q$. We then calculated the quantal content $(m)$ of the TS-eEPSCs dividing the amplitude of the TS-eEPSC (elicited by a regular concentric electrode on the TS) by the amplitude of the sfEPSC (elicited by the theta electrode) in the same cell. We found that the quantal content $(m)$ was significantly smaller in CIH neurons (Con: $24.3 \pm 2.4$, $n=22$, vs CIH: $12.2 \pm 1.3, n=22, p<0.0001$; Fig. $8 G$ ) while the percentage of failures, an index of the release probability since we are presumably recording from single terminals, was similar in both groups (Con: $37.5 \pm 6.0 \%, n=11$, vs CIH: $41.0 \pm 3.6 \%, n=$ $11, p=0.62$; Fig. $8 H$ ). Considering that the quantal content is the product of $n$ and $P_{R}$ and also that we observed no changes in the release probability, in different experimental protocols, we conclude that the depression of the TS-eEPSCs is a result of a reduction of the quantal parameter $n$, indicating a decrease in the number of active synapses.
Table 1. Parameters of the mEPSCs recorded in low latency-SD NTS neurons from control and $\mathrm{ClH}$ rats

\begin{tabular}{llll}
\hline & Frequency $(\mathrm{Hz})$ & Amplitude $(\mathrm{pA})$ & Half-width $(\mathrm{ms})$ \\
\hline Control $(n=9)$ & $0.99 \pm 0.25$ & $27.7 \pm 2.0$ & $2.61 \pm 0.23$ \\
$\mathrm{CIH}(n=13)$ & $1.61 \pm 0.26$ & $31.2 \pm 1.7$ & $2.65 \pm 0.22$ \\
$P$ & 0.119 & 0.205 & 0.908 \\
\hline
\end{tabular}

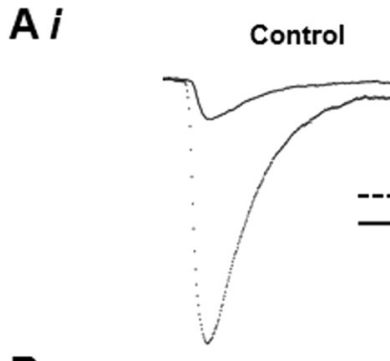

B

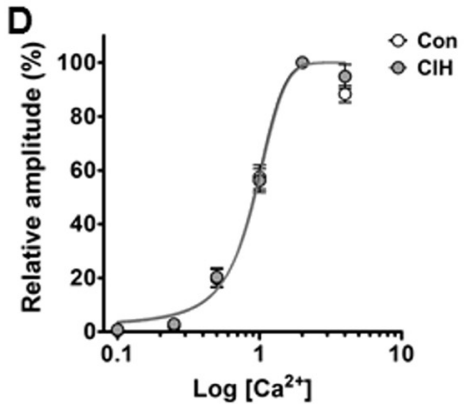

ii $\quad \mathrm{ClH}$

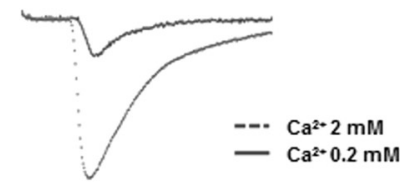

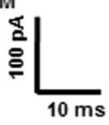

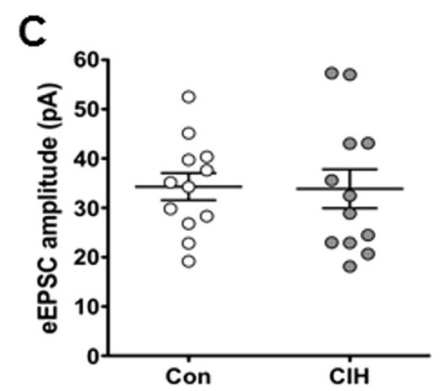

E

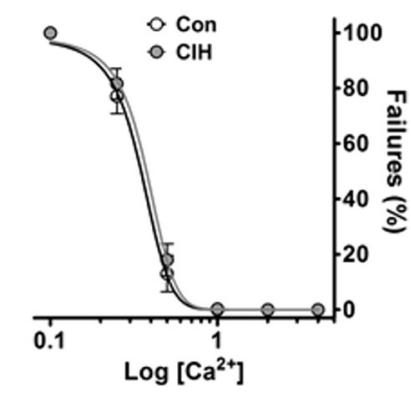

Figure 5. Evoked neurotransmission in control and CIH NTS neurons at different release probability conditions produced by changing external $\mathrm{Ca}^{2+}$. $\boldsymbol{A}$, Representative traces of TS eEPSCS from control (i) and $\mathrm{CIH}$ (ii) animals in normal ( $2 \mathrm{~mm}$; dotted line) and low ( $0.2 \mathrm{~mm}$; solid line) external $\mathrm{Ca}^{2+}$. B. Cumulative histogram of amplitudes of the TS-eEPSCs evoked in reduced $\mathrm{Ca}^{2+}$ in control (Con; $n=12)$ and CIH ( $n=12)$ neurons. C, Mean amplitude of the TS-eEPSC evoked in reduced $\mathrm{Ca}^{2+}$ of NTS neurons from Con and CIH animals. The symbols represent the average TS-eEPSC peak amplitude from individual neurons and the lines correspond to the group mean \pm SEM. $\boldsymbol{D}$, Calcium dose-response curve for the normalized TS-eEPSC amplitude. The data were normalized by the TS-eEPSC amplitudes obtained in $2 \mathrm{~mm}$ external calcium. The fitted curves correspond to logistic functions with variable slope. $\boldsymbol{E}$, Calcium dose-response curve for the TS-eEPSC failure rate. The points were fitted with a logistic function with variable slope; $n=11$ in both groups.

To make this model even more consistent, we predicted that although sfEPSCs were similar in control and CIH animals, a progressive fiber recruitment by increasing stimulus intensity would lead to comparable increases in the TS-eEPSC amplitudes in NTS neurons from both groups up to certain point from which the eEPSC amplitudes of CIH neurons would reach saturation, while the eEPSCs of NTS neurons from the control group would keep responding to the increasing stimulation intensity. To test this prediction, we performed intensity-response curves in NTS neurons from both control and $\mathrm{CIH}$ rats using the theta glass electrode and verified that our prediction was correct, because the TS-eEPSCs in both groups presented similar amplitudes until stimulus intensity increments of $15 \mathrm{~V}$ above the sfEPSC threshold [comparison of the 
A

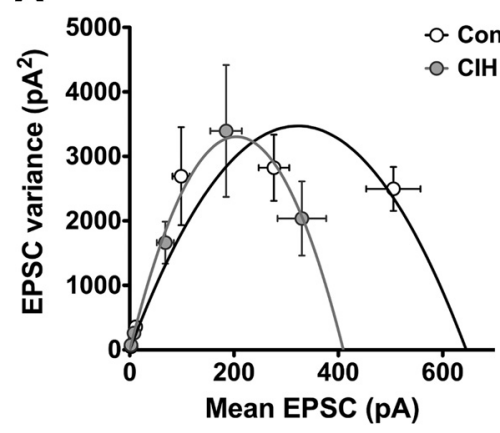

C

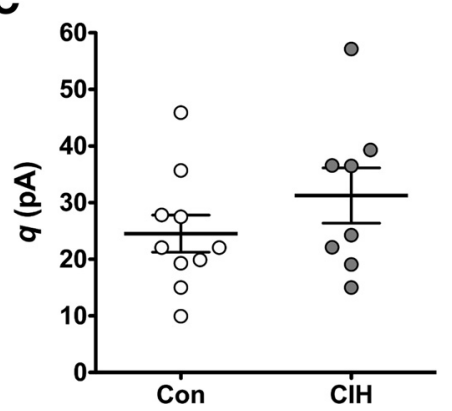

B

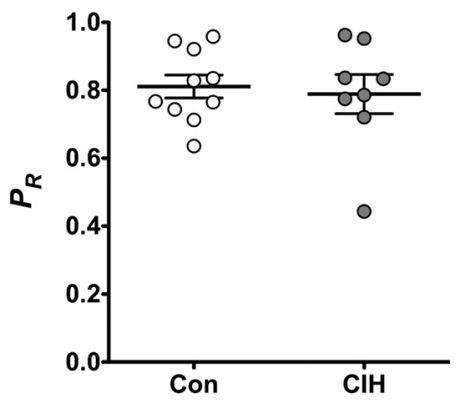

D

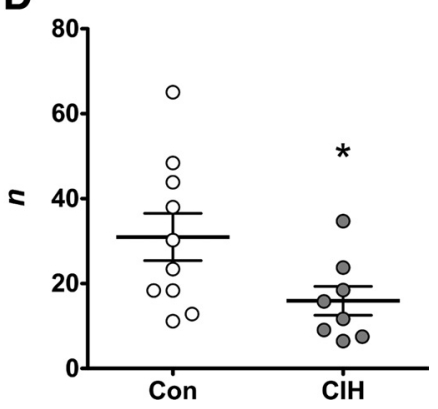

Figure 6. V-Manalysis of the TS-eEPSCS.A,Variance-mean analysis of the averaged data shown in Figure 5D (except $4 \mathrm{~mm}$ calcium). The data were fitted with a square hyperbolic function. Only the individual cells whose points were fitted by the quadratic function were included. B, Quantal size (q) of control (Con) and CIHTS-eEPSCs estimated by V-M analysis. C, Quantal parameter $n$ of Con and CIHTS-eEPSCS predicted by V-M analysis. $D$, Release probability $\left(P_{R}\right)$ of Con $(n=10)$ and CIH $(n=8)$ TS-eEPSCs. ${ }^{*} p=0.046$, unpaired $t$ test.

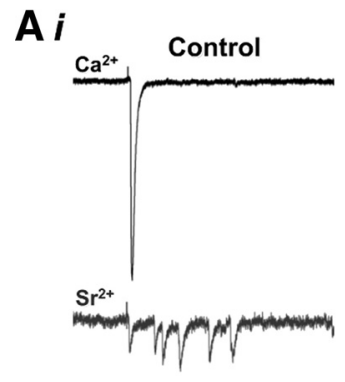

C
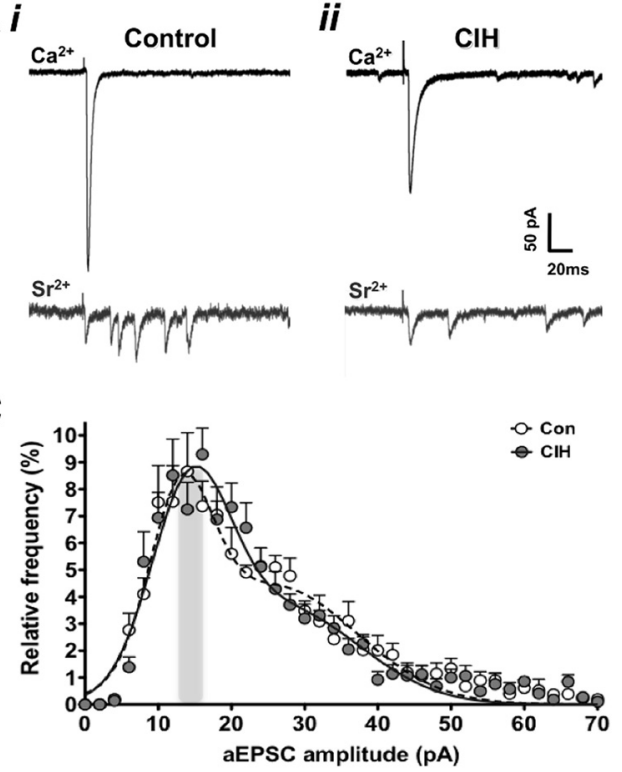

B

D

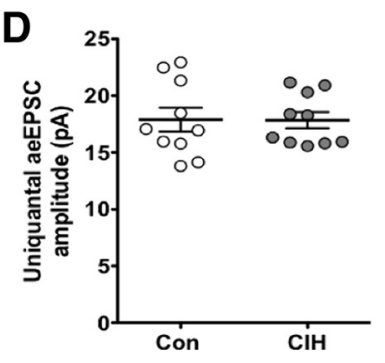

Figure 7. Asynchronous-evoked neurotransmission in the presence of $\mathrm{Sr}^{2+} . \boldsymbol{A}, \mathrm{TS}$-eEPSCs evoked in control conditions $\left(\mathrm{Ca}^{2+}\right)$ and in the presence of $\mathrm{Sr}^{2+}(2 \mathrm{~mm})$ in control (Con) (i) and CIH (ii) NTS neurons. $\boldsymbol{B}$, Number of aEPSCs evoked per trial in NTS neurons from Con ( $n=12$ ) and CIH animals $(n=12) .{ }^{* *} p=0.004$, Mann-Whitney test. C, Frequency distribution of the amplitudes of aEPSC $\operatorname{in}$ Con (clear circles) and CIH NTS neurons (dark circles). The lines represent the fit of a double Gaussian function to the data (Con, dotted line; CIH, solid line). The gray region corresponds to the peak of the first Gaussian curve from which we obtained the amplitude of uniquantal aEPSCS shown in $\boldsymbol{D}$. D, Mean amplitude of the uniquantal aEPSCs of Con $(n=12)$ and $\mathrm{CIH}(n=12)$ neurons.

slope obtained by linear regression: Con $(n=9-11)$ vs $\mathrm{CIH}(n=$ $10-11): 3.218$ vs 3.767; extra sum-of-squares $F$ test, $F_{(1,80)}=0.1022$, $p=0.750$; Figure 8I]. After this point, additional increases in the stimulus intensity produced a linear increase of eEPSC amplitude in the control group, while the eEPSC amplitudes in the $\mathrm{CIH}$ neurons reached a plateau (Fig. 8I). The comparison of the equations that define the linear regression for each group confirms that beyond an increment of $15 \mathrm{~V}$ in stimulus intensity, the profile of the curves and consequently the amplitudes of the eEPSCs is statistically different between groups [Con: $y=4.76 \times-11.05(n=7-9)$ vs $\mathrm{CIH}: y=$ $-0.48 \times+84.12(n=3-10)$; extra sum-ofsquares $F$ test, $F_{(2,74)}=5.477, p=0.0061$; Fig. 8I]. This observation is consistent with the proposed model in which the number of active synapses (the quantal parameter $n$ ) is reduced in NTS neurons of CIH rats, resulting in a decrease of the maximum TSevoked EPSC.

\section{Discussion}

The present study shows that $\mathrm{CIH}$ depresses the TS-evoked glutamatergic postsynaptic currents by decreasing the number of active synapses. Our findings presented no evidence of $\mathrm{CIH}$-induced changes in vesicular release probability or in the number or conductance of the postsynaptic non-NMDA receptors. Considering that both non-NMDA and NMDA currents are equally depressed, we propose that $\mathrm{CIH}$ produces a loss of active synapses either at the presynaptic or the postsynaptic site.

Our conclusions are based upon a series of experiments designed to test the mechanisms underlying $\mathrm{CIH}$-induced synaptic depression. First, we observed no change in relative short-term synaptic depression, which is expected to be reduced if release probability is decreased (Brenowitz et al., 1998; Brenowitz and Trussell, 2001). In fact, we demonstrated that decreasing release probability, via activation of $\mathrm{GABA}_{\mathrm{B}}$ receptors, diminishes the relative short-term depression of the TSeEPSCs. Second, we did not detect differences in the $\mathrm{Ca}^{2+}$-sensitivity of the TSeEPSC amplitude induced by $\mathrm{CIH}$. Third, the $P_{R}$ estimated by $V-M$ analysis did not change after $\mathrm{CIH}$. Altogether, these results are not consistent with a possible effect of $\mathrm{CIH}$ on decreasing the release probability of TS synaptic vesicles. Fourth, we demonstrated that there is no relevant decrease in the quantal size by different experimental protocols: (1) recordings of miniature spontaneous EPSCs, (2) TS-eEPSCs elicited in a low $P_{R}$ (low external $\left.\mathrm{Ca}^{2+}\right),(3)$ q estimation through $V-M$ analysis, (4) asynchronous TS-eEPSCs (in the presence of $\mathrm{Sr}^{2+}$ ), and (5) single-fiber TSeEPSCs.

Interestingly, we observed a very small reduction in the quantal TS-eEPSC amplitude evoked by single-fiber stimulation. However, this reduction (9\%) is not enough to account for the depression of the multifiber synaptic current $(53 \%)$. The obser- 

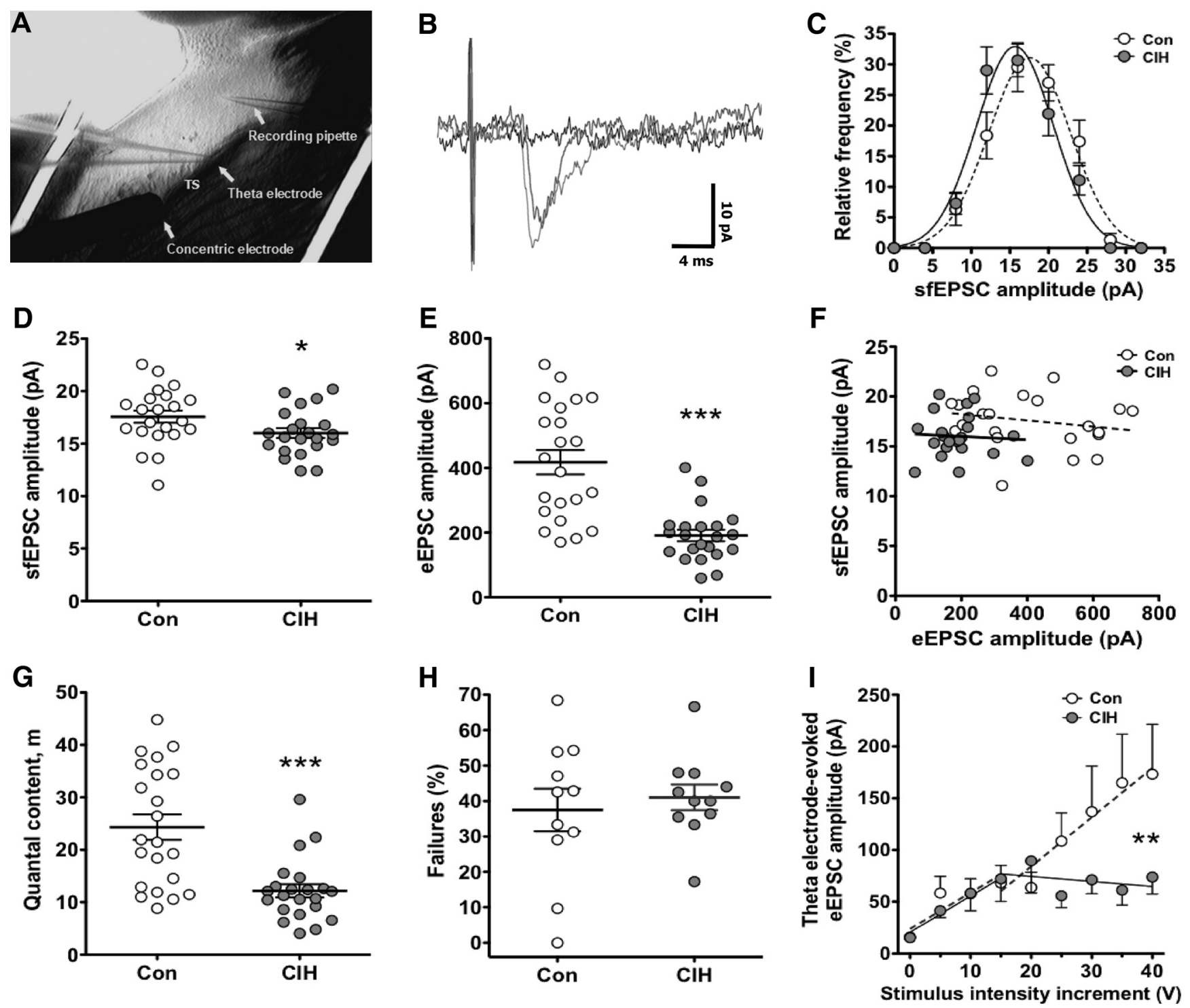

Figure 8. EPSCS evoked by single-fiber TS stimulation in low latency-SD NTS neurons of control (Con) and CIH animals. $A$, Photomicrograph showing a horizontal brainstem slice containing the intermediate NTS and the stimulating (concentric and theta) electrodes and recording pipette. $\boldsymbol{B}$, Representative single-fiber eEPSC recordings and failure to stimulation. $\boldsymbol{C}$, Amplitude frequency distribution of the TS-eEPSCs of NTS neurons of Con $(n=22)$ and $\mathrm{CIH}(n=22)$ animals obtained by single afferent fiber stimulation. The lines represent single Gaussian fits (Con, dashed line; $\mathrm{ClH}$, solid line), which indicates that sfEPSC s are uniquantal. $D$, Amplitude of sfEPSCs of NTS neurons of Con ( $n=22)$ and CIH ( $n=22)$ animals produced by theta-electrode stimulation of TS. ${ }^{*} p=0.042$, unpaired $t$ test. $\boldsymbol{E}$, Amplitude of TS-eEPSCs of NTS cells of Con and CIH animals obtained by TS-multifiber stimulation (by concentric electrode). ${ }^{* * *} p<0.0001$, Mann-Whitney test. $\boldsymbol{F}$, Graph showing the absence of correlation between eEPSC and sfEPSC amplitudes for the 22 cells studied in Con animals (open circles) and for the 22 cells studied in CIH animals (gray circles). G, Quantal content of the TS-eEPSCS in control and CIH NTS neurons. ${ }^{* * *} p=0.0004$, Mann-Whitney test. $\boldsymbol{H}$, Percentage of failures to single-fiber stimulation in NTS neurons from both Con and CIH animals. I, Changes in the amplitude of eEPSCs, evoked by theta-glass electrode stimulation of TS, produced by systematic increases in stimulus intensity. The point labeled " 0 " corresponds to minimal sfEPSC. ** $p=$ 0.0031, two-way ANOVA, CIH ( $n=3-11)$, Con ( $n=7-11)$. For stimulus increments from 0 to $15 \mathrm{~V}$ the linear regressions of the data in Con (dashed) and CIH (solid) are similar ( $p=0.89$, extra sum-of-squares $F$ test), whereas in between 15 and $40 \mathrm{~V}$ the regression lines are significantly different ( $p=0.0061$; extra sum-of-squares $F$ test).

vation that such effect was not present when we used low calcium and strontium can be explained since the TS-eEPSCs evoked in those experimental conditions are potentially contaminated with multiquantal and multifiber events, which probably masked the small reduction in the quantal TS-eEPSC evidenced by singlefiber stimulation. Additionally, we did not detect a decrease of the quantal size in $\mathrm{CIH}$ synapses estimated by $V$ - $M$ analysis; however, the $q$ values obtained with this method are weighted $q$ value, which emphasizes synapses with greater quantal size.

In line with the lack of evidence for a reduction in $P_{r}$ or quantal TS-eEPSC amplitude, three main findings point directly to a reduced number of functional synapses as the mechanism for CIH-induced decrease in TS-eEPSC amplitude: (1) the reduced number of aEPSCs elicited per trial, (2) the earlier plateau in neurons from $\mathrm{CIH}$ animals for the intensity-response curve of the TS-eEPSC amplitude, (3) the decreased quantal content of the TS-eEPSCs, and (4) the reduced $n$ in CIH synapses obtained in the $V-M$ analysis. Based upon this strong experimental evidence, we propose that the CIH-induced depression of the TSevoked EPSCs is due to a reduction of the number of functional synapses (the quantal parameter $n$ ), which in turn reduces the quantal content (the quantal parameter $m$ ) of the EPSC (Del Castillo and Katz, 1954). This model is compatible with the observed reduction in $1 / \mathrm{CV}^{2}$ of the TS-eEPSCs because this parameter is sensitive not only to changes in $P_{r}$ but also to changes in $n$ $\left[1 / \mathrm{CV}^{2}=\left(n \cdot P_{R}\right) /\left(1-P_{R}\right)\right.$; Malinow and Tsien, 1990)]. Addi- 
tionally, this model is in line with the increased likelihood of occurrence of failures during a high-frequency train of stimuli as well as the rightward shift of the $\mathrm{IC}_{50}$ for $\mathrm{Ca}^{2+}$ dose-response curve for failure rate after $\mathrm{CIH}$, since a decrease of $n$ would produce an increased failure rate.

Several changes can contribute to reduce the number of functional synapses, which may occur both presynaptically (Moulder et al., 2004; Voronin and Cherubini, 2004; Enoki et al., 2009; Doussau et al., 2010) or postsynaptically (Nägerl et al., 2004). At presynaptic level it may represent a decrease in releasable vesicles, active zones, or terminals, and postsynaptically it could reflect dendrite spine retraction or complete removal of postsynaptic glutamatergic receptors. Our data clearly demonstrate that $\mathrm{CIH}$ induced depression is also detected measuring NMDA currents, which discard a postsynaptic silencing due to a selective removal of non-NMDA receptors. Thus, CIH seems to produce a complete synaptic silencing (Voronin and Cherubini, 2004) either postsynaptically or presynaptically, rather than specifically affecting non-NMDA receptors as seen in several forms of LTD (Lüscher et al., 1999; Lüthi et al., 1999; Collingridge et al., 2010).

\section{Physiological significance of the $\mathrm{CIH}$-induced depression of glutamatergic transmission from the TS}

$\mathrm{CIH}$ is an important pathophysiological challenge that leads to intermittent and sustained increases in the discharge of visceral peripheral afferent inputs in the NTS, such as those arising from the peripheral chemoreceptors and arterial baroreceptors (Fletcher et al., 1992; Vidruk et al., 2001; Peng et al., 2003; Zoccal et al., 2008), leading to a remarkable increase in the traffic of information to the NTS during each hypoxic episode. The increased activity in the TS afferents could be the cause of activitydependent homeostatic plasticity (Turrigiano, 2008) in the NTS afferent neurotransmission, which is expressed as a depression of the neurotransmission aiming the stabilization of neuronal circuitry function under the pathophysiological circumstances of the recurrent cycles of hypoxia and normoxia of our protocol. More specifically, this adaptive homeostatic plasticity could be expressed as a potential LTD of glutamatergic afferent neurotransmission, which has been described in NTS (Zhou et al., 1997) and could be, at least in part, related to the CIH-induced depression, albeit the mechanisms of LTD described by Zhou et al. (1997) are distinct of those herein observed.

Although it is plausible to propose that $\mathrm{CIH}$ induces a form of LTD in overexcited TS synapses, we cannot discard the possibility that CIH-induced synaptic depression in the NTS is a consequence of downregulatory mechanisms of initially potentiated synapses (Collingridge et al., 2010). This hypothesis would imply that a reasonable fraction of TS synapses are in a potentiated state before $\mathrm{CIH}$ and this challenge would reverse this potentiation. Interestingly, the distribution of the eEPSC amplitudes of the low latency-SD synapses in NTS neurons from control rats presents a bigger kurtosis $(-0.668)$ than NTS neurons from CIH rats $(-0.052)$, suggesting that $\mathrm{CIH}$ is mainly affecting stronger synapses (Fig. $1 D$ ), which could represent potentiated synapses.

\section{Which NTS afferents are affected by CIH?}

Both baroreflex and chemoreflex pathways are known to be affected by CIH (Peng et al., 2003; Braga et al., 2007; Zoccal et al., 2009). We recently described (Accorsi-Mendonça et al., 2011) the characteristics of the TS-eEPSCs from morphologically identified neurons receiving afferents from the CB-NTS neurons (chemosensory synapses) and the aortic depression nerve (ADN-NTS neurons; barosensory synapses). CB-NTS eEPSCs presented higher variability in their latencies than ADN-NTS EPSCs in a range previously assumed to be characteristic of higher order neurons (Doyle and Andresen, 2001; Bailey et al., 2006). Surprisingly, in the present study we found that $\mathrm{CIH}$ affects synapses with a low variability of eEPSC latencies consistent with barosensory synapses but produces no changes in synapses with variability of their eEPSC latencies in the range of the peripheral chemosensory afferents (Accorsi-Mendonça et al., 2011). Therefore, these data, combined with our previous studies, suggest that $\mathrm{CIH}$-induced synaptic depression is restricted to second-order neurons probably integral to the baroreflex pathways and could be an adaptation to increased blood pressure and recurrent baroreceptor activation in response to each episode of intermittent hypoxia.

Nevertheless, we cannot state that chemosensory synapses are not affected by $\mathrm{CIH}$, because in the present study they probably represent a fraction of the synapses with TS-eEPSC latency variability $>0.25 \mathrm{~ms}$, and any effect on these specific synapses could be masked by other $\mathrm{CIH}$ nonresponsive synapses with similar TS-eEPSC latency variability. On the other hand, chemosensory synapses could even present a different pattern of responses to CIH. For instance, de Paula et al. (2007) showed that CIH enhanced non-NMDA currents, elicited by exogenous application of the glutamatergic non-NMDA agonist AMPA, in dissociated NTS neurons receiving inputs from the CB.

Finally, the different mechanisms of depression proposed herein and by Kline et al. (2007) might potentially represent distinct mechanisms of $\mathrm{CIH}$-induced synaptic depression acting on different populations of NTS neurons. For instance, Kline et al. (2007) recorded from caudal NTS neurons showing TS-eEPSCs with an "all-or-none" fashion, while we recorded from intermediate and caudal NTS neurons, and did not restrict our recordings to "all-or-none" synapses. Thus, it is possible that CIH might have different effects on the afferent transmission in different populations of NTS neurons.

\section{Conclusions}

Our findings strongly support the concept that $\mathrm{CIH}$ selectively depresses afferent neurotransmission in putative barosensitive second-order NTS neurons by a reduction in the number of functional synapses. This effect is a likely result of activity-dependent plasticity due to the overexcitation of barosensitive afferent inputs during $\mathrm{CIH}$ exposition, which could be a homeostatic response to the increased activity of these synapses. These data open new perspectives for a better understanding of the mechanisms underlying the synaptic plasticity in the brainstem sensory neurons under challenges like those produced by chronic intermittent hypoxia.

\section{References}

Accorsi-Mendonça D, Castania JA, Bonagamba LG, Machado BH, Leão RM (2011) Synaptic profile of nucleus tractus solitarius neurons involved with the peripheral chemoreflex pathways. Neuroscience 197:107-120. CrossRef Medline

Allen C, Stevens CF (1994) An evaluation of causes for unreliability of synaptic transmission. Proc Natl Acad Sci U S A 91:10380-10383. CrossRef Medline

Andresen MC, Kunze DL (1994) Nucleus tractus solitarius-gateway to neural circulatory control. Annu Rev Physiol 56:93-116. CrossRef Medline

Bailey TW, Jin YH, Doyle MW, Smith SM, Andresen MC (2006) Vasopressin inhibits glutamate release via two distinct modes in the brainstem. J Neurosci 26:6131-6142. CrossRef Medline

Bekkers JM, Clements JD (1999) Quantal amplitude and quantal variance of strontium-induced asynchronous EPSCs in rat dentate granule neurons. J Physiol 516:227-248. CrossRef Medline 
Blitz DM, Foster KA, Regehr WG (2004) Short-term synaptic plasticity: a comparison of two synapses. Nat Rev Neurosci 5:630-640. CrossRef Medline

Braga VA, Soriano RN, Braccialli AL, de Paula PM, Bonagamba LG, Paton JF, Machado BH (2007) Involvement of L-glutamate and ATP in the neurotransmission of the sympathoexcitatory component of the chemoreflex in the commissural nucleus tractus solitarii of awake rats and in the working heart-brainstem preparation. J Physiol 581:1129-1145. CrossRef Medline

Brenowitz S, Trussell LO (2001) Minimizing synaptic depression by control of release probability J Neurosci 21:1857-1867.

Brenowitz S, David J, Trussell L (1998) Enhancement of synaptic efficacy by presynaptic GABA(B) receptors. Neuron 20:135-141, 1998 Jan. CrossRef Medline

Chen CY, Horowitz JM, Bonham AC (1999) A presynaptic mechanism contributes to depression of autonomic signal transmission in NTS. Am J Physiol 277:H1350-1360. Medline

Clements JD (2003) Variance-mean analysis: a simple and reliable approach for investigating synaptic transmission and modulation. J Neurosci Methods 130:115-125. CrossRef Medline

Clements JD, Silver RA (2000) Unveiling synaptic plasticity: a new graphical and analytical approach. Trends Neurosci 23:105-113. CrossRef Medline

Collingridge GL, Peineau S, Howland JG, Wang YT (2010) Long-term depression in the CNS. Nat Rev Neurosci 11:459-473. CrossRef Medline

Del Castillo J, Katz B (1954) Quantal components of the end-plate potential. J Physiol 124:560-573. Medline

de Paula PM, Tolstykh G, Mifflin S (2007) Chronic intermittent hypoxia alters NMDA and AMPA-evoked currents in NTS neurons receiving carotid body chemoreceptor inputs. Am J Physiol Regul Integr Comp Physiol 292:R2259-R2265. CrossRef Medline

Dobrunz LE, Stevens CF (1997) Heterogeneity of release probability, facilitation, and depletion at central synapses. Neuron 18:995-1008. CrossRef Medline

Doussau F, Humeau Y, Benfenati F, Poulain B (2010) A novel form of presynaptic plasticity based on the fast reactivation of release sites switched off during low-frequency depression. J Neurosci 30:16679-16691. CrossRef Medline

Doyle MW, Andresen MC (2001) Reliability of monosynaptic sensory transmission in brain stem neurons in vitro. J Neurophysiol 85:22132223. Medline

Doyle MW, Bailey TW, Jin YH, Appleyard SM, Low MJ, Andresen MC (2004) Strategies for cellular identification in nucleus tractus solitarius slices. J Neurosci Methods 137:37-48.

Enoki R, Hu YL, Hamilton D, Fine A (2009) Expression of long-term plasticity at individual synapses in hippocampus is graded, bidirectional, and mainly presynaptic: optical quantal analysis. Neuron 62:242-253. CrossRef Medline

Fletcher EC, Lesske J, Qian W, Miller CC 3rd, Unger T (1992) Repetitive, episodic hypoxia causes diurnal elevation of blood pressure in rats. Hypertension 19:555-561. CrossRef Medline

Fortin G, Velluti JC, Denavit-Saubié M, Champagnat J (1992) Responses to repetitive afferent activity of rat solitary complex neurons isolated in brainstem slices. Neurosci Lett 147:89-92. CrossRef Medline

Franks KM, Isaacson JS (2006) Strong single-fiber sensory inputs to olfactory cortex: implications for olfactory coding. Neuron 49:357-363. CrossRef Medline

Glaum SR, Brooks PA (1996) Tetanus-induced sustained potentiation of monosynaptic inhibitory transmission in the rat medulla: evidence for a presynaptic locus. J Neurophysiol 76:30-38. Medline

Isaac JT, Hjelmstad GO, Nicoll RA, Malenka RC (1996) Long-term potentiation at single fiber inputs to hippocampal CA1 pyramidal cells. Proc Natl Acad Sci U S A 93:8710-8715. CrossRef Medline

Kerchner GA, Nicoll RA (2008) Silent synapses and the emergence of a postsynaptic mechanism for LTP. Nat Rev Neurosci 9:813-825. CrossRef Medline

Kline DD, Ramirez-Navarro A, Kunze DL (2007) Adaptive depression in synaptic transmission in the nucleus of the solitary tract after in vivo chronic intermittent hypoxia: evidence for homeostatic plasticity. J Neurosci 27:4663-4673. CrossRef Medline

Lüscher C, Xia H, Beattie EC, Carroll RC, von Zastrow M, Malenka RC, Nicoll RA (1999) Role of AMPA receptor cycling in synaptic transmission and plasticity. Neuron 24:649-658. CrossRef Medline

Lüthi A, Chittajallu R, Duprat F, Palmer MJ, Benke TA, Kidd FL, Henley JM, Isaac JT, Collingridge GL (1999) Hippocampal LTD expression involves a pool of AMPARs regulated by the NSF-GluR2 interaction. Neuron 24: 389-399. CrossRef Medline

Malinow R, Tsien RW (1990) Presynaptic enhancement shown by wholecell recordings of long-term potentiation in hippocampal slices. Nature 346:177-180. CrossRef Medline

Moulder KL, Meeks JP, Shute AA, Hamilton CK, de Erausquin G, Mennerick S (2004) Plastic elimination of functional glutamate release sites by depolarization. Neuron 42:423-435. CrossRef Medline

Nägerl UV, Eberhorn N, Cambridge SB, Bonhoeffer T (2004) Bidirectional activity-dependent morphological plasticity in hippocampal neurons. Neuron 44:759-767. CrossRef Medline

Oliet SH, Malenka RC, Nicoll RA (1996) Bidirectional control of quantal size by synaptic activity in the hippocampus. Science 271:1294-1297. CrossRef Medline

Peng YJ, Overholt JL, Kline D, Kumar GK, Prabhakar NR (2003) Induction of sensory long-term facilitation in the carotid body by intermittent hypoxia: implications for recurrent apneas. Proc Natl Acad Sci U S A 100: 10073-10078. CrossRef Medline

Peters JH, McDougall SJ, Fawley JA, Smith SM, Andresen MC (2010) Primary afferent activation of thermosensitive TRPV1 triggers asynchronous glutamate release at central neurons. Neuron 65:657-669. CrossRef Medline

Raastad M, Storm JF, Andersen P (1992) Putative single quantum and single fibre excitatory postsynaptic currents show similar amplitude range and variability in rat hippocampal slices. Eur J Neurosci 4:113-117. CrossRef Medline

Stevens CF, Wang Y (1994) Changes in reliability of synaptic function as a mechanism for plasticity. Nature 371:704-707. CrossRef Medline

Turrigiano GG (2008) The self-tuning neuron: synaptic scaling of excitatory synapses. Cell 135:422-435. CrossRef Medline

Tzounopoulos T, Rubio ME, Keen JE, Trussell LO (2007) Coactivation of pre- and postsynaptic signaling mechanisms determines cell-specific spike-timing-dependent plasticity. Neuron 54:291-301. CrossRef Medline

Vidruk EH, Olson EB Jr, Ling L, Mitchell GS (2001) Responses of singleunit carotid body chemoreceptors in adult rats. J Physiol 531:165-170. CrossRef Medline

Voronin LL, Cherubini E (2004) 'Deaf, mute and whispering' silent synapses: their role in synaptic plasticity. J Physiol 557:3-12. CrossRef Medline

Xu-Friedman MA, Regehr WG (2000) Probing fundamental aspects of synaptic transmission with strontium. J Neurosci 20:4414-4422. Medline

Xu-Friedman MA, Regehr WG (2004) Structural contributions to shortterm synaptic plasticity. Physiol Rev 84:69-85. CrossRef Medline

Yamamoto K, Noguchi J, Yamada C, Watabe AM, Kato F (2010) Distinct target cell-dependent forms of short-term plasticity of the central visceral afferent synapses of the rat. BMC Neurosci 11:134. Medline

Zhou Z, Champagnat J, Poon CS (1997) Phasic and long-term depression in brainstem nucleus tractus solitarius neurons: differing roles of AMPA receptor desensitization. J Neurosci 17:5349-5356. Medline

Zoccal DB, Simms AE, Bonagamba LG, Braga VA, Pickering AE, Paton JF, Machado BH (2008) Increased sympathetic outflow in juvenile rats submitted to chronic intermittent hypoxia correlates with enhanced expiratory activity. J Physiol 586:3253-3265. CrossRef Medline

Zoccal DB, Bonagamba LG, Paton JF, Machado BH (2009) Sympatheticmediated hypertension of awake juvenile rats submitted to chronic intermittent hypoxia is not linked to baroreflex dysfunction. Exp Physiol 94: 972-983. CrossRef Medline 